\title{
Description of Hypogastrura ellisi sp. n. with notes on $H$. tethyca Ellis and the trybomi group (Collembola, Hypogastruridae)
}

\author{
Dariusz Skarżyński', Morteza Kahrarian², Agata Piwnik', Marlena Zawisza' \\ I Institute of Environmental Biology, University of Wroctaw, Przybyszewskiego 65, 51-148 Wroctaw, Poland \\ 2 Young researchers and elite club, Kermanshah branch, Islamic Azad University, Kermanshah, Iran \\ Corresponding author: Dariusz Skarżyński (dariusz.skarzynski@uwr.edu.pl)
}

Academic editor: W.M. Weiner | Received 30 June 2017 | Accepted 2 November 2017 | Published 7 December 2017

http://zoobank.org/372CA647-F8BF-4AD7-BFBD-93856296B756

Citation: Skarżyński D, Kahrarian M, Piwnik A, Zawisza M (2017) Description of Hypogastrura ellisi sp. n. with notes on H. tethyca Ellis and the trybomi group (Collembola, Hypogastruridae). ZooKeys 719: 45-57. https://doi. org/10.3897/zookeys.719.14806

\begin{abstract}
A new species, Hypogastrura ellisi, from Iran and Greece is described. It does not fit the definition of any known species group, but, as it has weakly differentiated blunt Ant. IV sensilla, one tenent hair on tibiotarsi, broad empodial lamellae, and dens with fine granulation and seven setae, it can be compared with some members of the trybomi and monticola groups and H. aterrima Yosii, 1972. It seems to be especially close to a representative of the trybomi group, H. tethyca Ellis, 1976. They differ mainly in the shape of apical papillae on the labrum, the size of anal spines, and the presence of setae $\mathrm{m}_{2}$ on Th. II. Notes on $H$. tethyca, the trybomi group, and a key to the species of the group are given.
\end{abstract}

\section{Keywords}

Azerbaijan, Greece, Iran, key, springtails, taxonomy

\section{Introduction}

Hypogastrura Bourlet, 1839 currently comprising 168 species (Bellinger et al. 1996-2017), is the most speciose genus within the family Hypogastruridae. Looking for phylogenetic relationships between them, and for practical reasons, the genus has been divided into some species groups based on morphology (Yosii 1960, Christiansen

Copyright Dariusz Skarżyński et al. This is an open access article distributed under the terms of the Creative Commons Attribution License (CC BY 4.0), which permits unrestricted use, distribution, and reproduction in any medium, provided the original author and source are credited. 
and Bellinger 1980, Babenko et al. 1994, Skarżyński 2009). Presently, nine groups are used in the taxonomy of the genus: crassaegranulata, manubrialis, monticola, nivicola, packardi, sahlbergi, socialis, trybomi, and viatica. This group system is not complete; numerous species do not belong to any of these groups due to their specific morphology or poor knowledge on their morphology. In the material collected in Iran, several specimens that resemble Hypogastrura tethyca Ellis, 1976, a member of the trybomi group, were found. Studies on the type material of this species made it possible to ascertain that the Iranian specimens represented a new species that does not fit the definition of any known species group. Its description, notes on $H$. tethyca and the trybomi group as a whole, as well as a key to all known species of the group are given below.

\section{Materials and methods}

Specimens of Hypogastrura ellisi sp. n. were cleared in Nesbitt's fluid (Wang et al. 2003), subsequently mounted on slides in Swan's medium (Swan 1936) and studied using a Nikon Eclipse E600 phase contrast microscope. Figures were drawn with the camera lucida. Photographs were made using a camera Nikon D5100 mounted on a microscope mentioned above. Photographs were stacked using Helicon Focus 6.7.1. and prepared for publication using Adobe Photoshop CS6.

Terminology for the description follows that given in Fjellberg (1984, 1999), Babenko et al. (1994) and Thibaud et al. (2004).

Abbreviations used:

Ant. I-IV

antennal segments I-IV,

Th. I-III

thoracic terga I-III,

Abd. I-VI

abdominal terga I-VI.

\section{Taxonomy}

Hypogastrura ellisi Skarżyński \& Kahrarian, sp. n. http://zoobank.org/C8F33D89-AEDF-45FB-B748-2078A73A5F2B

Figs $1-10$

Type material. Holotype: female on slide, litter in oak forest, Zagros Mountains, Dalab mountain $\left(33^{\circ} 34^{\prime} \mathrm{N}, 47^{\circ} 31^{\prime} \mathrm{E} / 1700 \mathrm{~m}\right.$ a.s.l.), Kohdasht County, Lorestan Province, Iran, 4.XII.2013, leg. M. Kahrarian. Paratypes: 4 females, 1 male, same data as holotype; 1 female, 1 male, litter in oak forest, Zagros Mountains, Sorkhdom

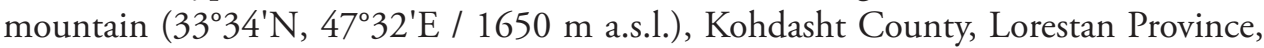
Iran, 14.XI.2013, leg. M. Kahrarian; 2 females, 1 male, litter in oak forest, Zagros Mountains, near Patogh ghaut $\left(34^{\circ} 25^{\prime} \mathrm{N}, 46^{\circ} 00^{\prime} \mathrm{E} / 1030 \mathrm{~m}\right.$ a.s.l.), Sarpol-e-zahab County, Kermanshah Province, Iran, 9.II.2014, leg. M. Kahrarian; 1 male, oak for- 


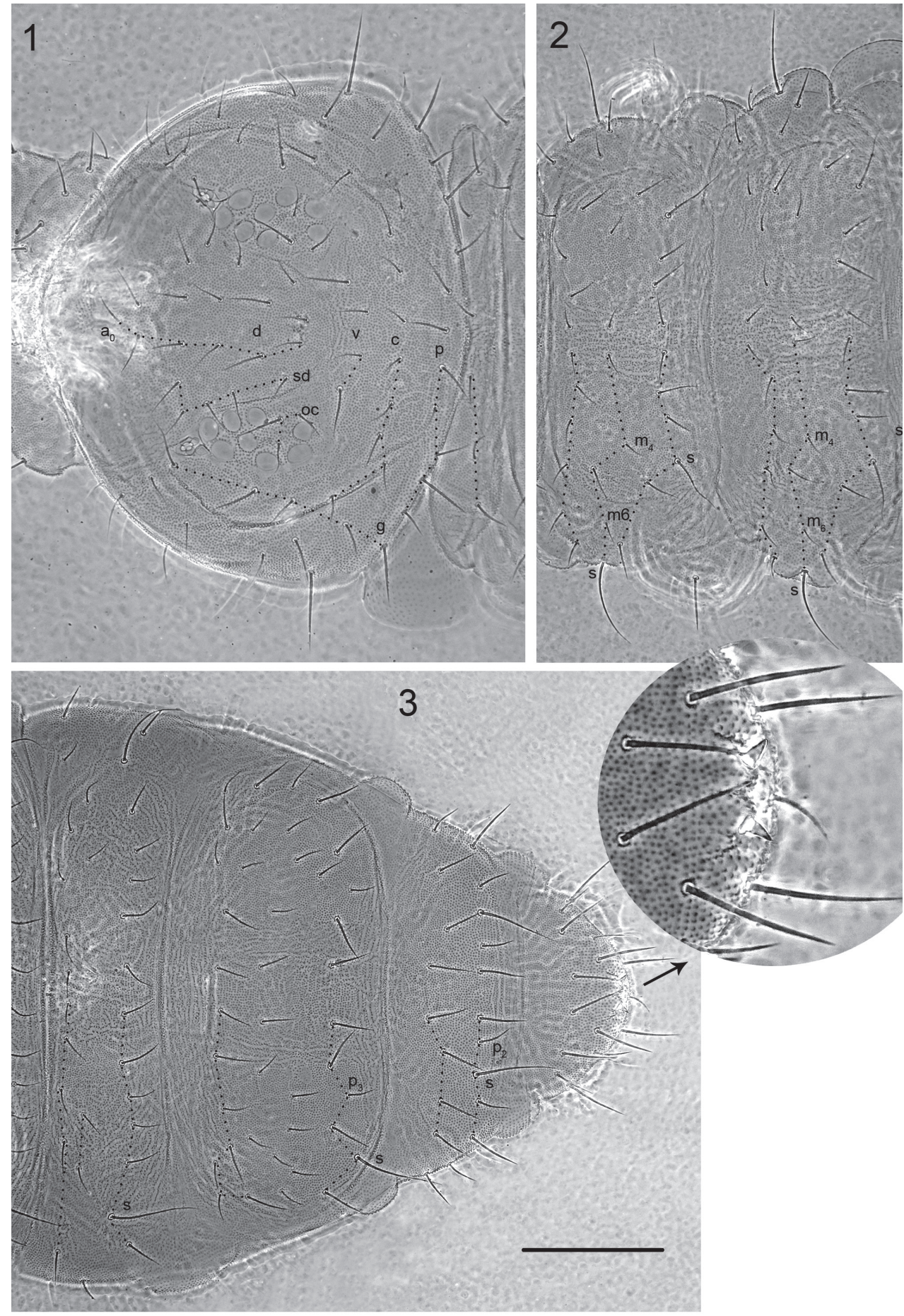

Figures I-3. Hypogastrura ellisi sp. n. I chaetotaxy of head and Th. I $\mathbf{2}$ chaetotaxy of Th. II-III $\mathbf{3}$ chaetotaxy of Abd. III-VI. Scale bar: $0.1 \mathrm{~mm}$. 
est, Zagros Mountains, near Shabankareh village (34 ${ }^{\circ} 52^{\prime} \mathrm{N}, 46^{\circ} 30^{\prime} \mathrm{E} / 1600 \mathrm{~m}$ a.s.l.), Paveh County, Kermanshah Province, Iran, 20.I.2014, leg. M. Kahrarian. Holotype and 7 paratypes deposited at the Department of Agronomy, Kermanshah Branch, Islamic Azad University, Kermanshah, Iran and 4 paratypes deposited in the collection of the Institute of Environmental Biology, University of Wrocław, Poland.

Other material. Greece, Lesbos, leg. Ellis (deposited at the Naturalis Biodiversity Center, Netherland): 22 females, 6 males (21038-21054, 21056-21059, 2106221064, 21066-21068), Antissa, 30.X.1973, 973240; 18 females, 23 males (21060, 21078-21117), Antissa, 30.X.1973, 973243; 1 male (21061), Antissa, 30.X.1973, 973244; 1 male (21037), Gavathas, 31.X.1973, 973247.

Etymology. Dedicated to Dr. Willem N. Ellis, an excellent specialist in Collembola.

Diagnosis. Habitus typical of genus. Ant. IV with three lateral and one dorsal long thin and curved blunt sensilla (sometimes 1-2 more in dorsal group, longer and less curved). Postantennal organ equal to, or slightly larger than, nearest ocellus. Labrum with distinct apical papillae. Tibiotarsi with one clavate tenent hair. Empodial lamellae broad. Ventral tube with $4+4$ setae. Retinaculum with $4+4$ teeth. Dens with fine, uniform granulation and seven setae. Mucro with comparatively high outer lamella. Anal spines small, situated on low basal papillae.

Description. Body length 1.1-1.6 mm. Habitus typical of the genus. Color in alcohol pale brown dorsally and yellowish ventrally, eye-patches dark. Granulation fine and uniform, 12-20 granules between setae $\mathrm{p}_{1}$ on Abd. V.

Chaetotaxy of head typical of the genus, with complete set of v-setae (Fig. 1). Setae slightly differentiated in length, especially on last abdominal segments, smooth and rather thick and stiff. Body sensilla (s) about 2-3 times longer than ordinary setae, fine and smooth. Dorsal chaetotaxy of Th. I-III and Abd. III-VI as in Figs 1-3. Th. I with $3+3$ setae. Th. II with setae $m_{2}$ absent, $m_{3}$ present or absent and $m_{4}, m_{6}$ present. Th. III with setae $m_{2}$ and $m_{3}$ absent and setae $m_{4}$ and $m_{6}$ present. Abd. IV with setae $p_{3}$ present, $\mathrm{p}_{7}$ absent and increased number of $\mathrm{m}$-setae. On Abd. V setae $\mathrm{p}_{2}$ present and $\mathrm{m}$-setae absent. Subcoxae I, II, III with 1, 3, 3 setae respectively. Microsensillum on Th. II present.

Ant. IV with simple apical vesicle, subapical organite (or), microsensillum (ms), three lateral and one dorsal long thin and curved blunt sensilla (sometimes 1-2 more in dorsal group, longer and less curved, marked with an asterisk in Fig. 4) and 5-10 short pointed setae in ventral file (Fig. 5). Ant. III-organ with two long (outer) and two short (inner) sensilla (Fig. 4). Microsensillum on Ant. III present. Ant. I with seven setae (seta p' absent).

Ocelli $8+8$. Postantennal organ equal to, or slightly larger than, neighboring ocellus, with four subequal lobes. Accessory boss present (Fig. 6). Labrum with six distinct apical papillae (four large and two smaller, Figs 9-10). Labral setae 5, 5, 4, prelabrals 4. Maxillary head of the H. tullbergi type (Fjellberg 1984) and labium as in Fjellberg (1999: fig. 6). Outer lobe of maxilla with two sublobal hairs.

Tibiotarsi I, II, III with 19, 19, 18 setae respectively. Apical seta A long and clavate. Claws with small inner tooth. Empodial appendage with broad basal lamella and apical filament reaching slightly beyond inner tooth of unguis (Fig. 7). 


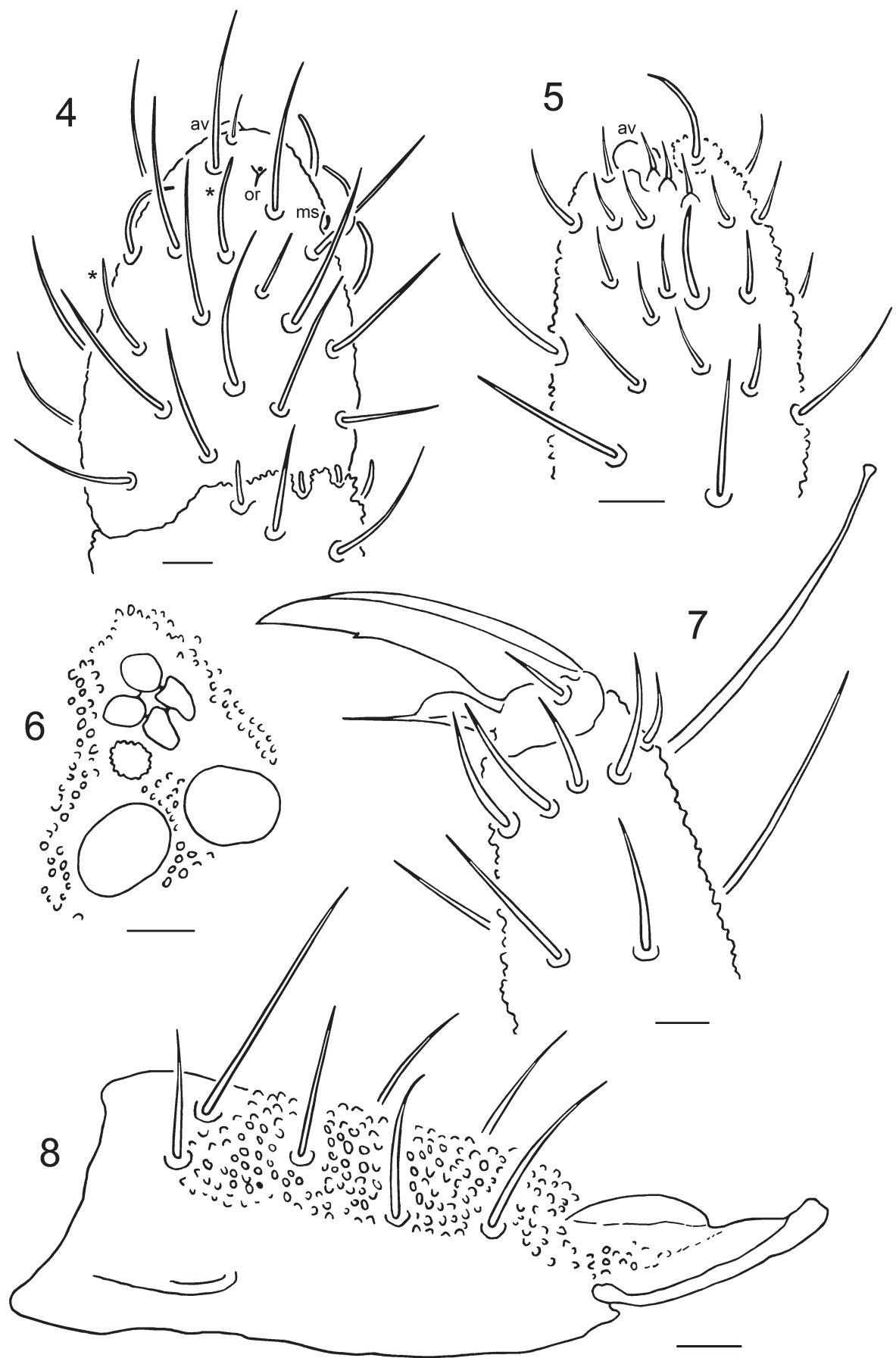

Figures 4-8. Hypogastrura ellisi sp. n. 4 chaetotaxy of dorsal side of Ant. IV 5 chaetotaxy of ventral side of Ant. IV $\mathbf{6}$ postantennal organ and neighbor ocelli $\mathbf{7}$ claw III $\mathbf{8}$ dens and mucro. Abbreviations in text. Scale bars: $0.01 \mathrm{~mm}$. 
Ventral tube with four setae on each side. Retinaculum with $4+4$ teeth.

Furca well developed (ratio dens + mucro/inner edge of claws III 2.4-2.7). Dorsal side of dens with fine, uniform granulation and seven setae. Mucro with relatively high outer lamella. Ratio dens/mucro 2.0-2.3 (Fig. 8).

Anal spines small, situated on low basal papillae (Fig. 3), ratio anal spine/basal papilla 0.7-1.1, ratio anal spine + basal papilla/inner edge of claws III 0.5-0.6.

Remarks. It is difficult to find a right place for $H$. ellisi sp. n. within the genus. This species does not key to any of the groups in Skarżyński (2009). However, having weakly differentiated blunt Ant. IV sensilla, one tenent hair on the tibiotarsi, broad empodial lamellae, dens without tooth-like granules and ventro-apical swelling and a mucro without a distinct subapical tooth, it can be compared with some representatives of the trybomi or monticola groups as well as H. aterrima Yosii, 1972, which has an isolated position within the genus.

Undoubtedly, $H$. ellisi sp. n. is the most similar to $H$. tethyca, considered as a member of the trybomi group. Most noticeably they differ in the shape of labral apical papillae (H. ellisi sp. n. - convex, strong, well visible, Figs 9-10; H. tethyca - flat, delicate, hardly visible, Figs 11-13). Apart from this $H$. ellisi sp. n. lacks setae $\mathrm{m}_{2}$ on Th. II (present in $H$. tethyca) and possesses smaller anal spines (the ratio of anal spine + basal papilla/inner edge of claws III $0.5-0.6$ in $H$. ellisi sp. n. vs $0.75-1.1$ in $H$. tethyca), 5-10 short pointed setae in the ventral file on Ant. IV (Fig. 5) (H. tethyca - approx. ten short and stiff sensilla, truncate at apex, Fig. 14), and a mucro with a relatively high outer lamella (both inner and outer lamellae are low in $H$. tethyca).

Both species have similar general ranges of distribution (H. ellisi sp. n.: Iran, Greece - Lesbos; H. tethyca: Greece - Crete, Lesbos and Azerbaijan), but on a local scale they co-occur only in Lesbos. In Ellis's material from this island, numerous $H$. ellisi sp. n. from two localities and rare $H$. tethyca individuals from five sites were found. Nevertheless, they were isolated spatially. Unfortunately, due to incomplete collecting data, we do not know whether these populations differ in habitat preferences.

The new species is easy to distinguish from the members of the monticola group by the absence of $\mathrm{m}$-setae on Abd. V (vs present) and the size of the postantennal organ, which is equal to, or slightly larger than, the neighboring ocellus (vs 1.5-2 times larger than ocellus). H. aterrima can also be easily separated from $H$. ellisi sp. n. due to tridentate retinaculum (vs quadridentate), minute anal spines, slightly larger than surrounding granules (vs large, the ratio of anal spine + basal papilla/inner edge of claws III 0.5-0.6 in H. ellisi sp. n.), the presence of setae $\mathrm{m}_{2}$ on Th. II, and the absence of setae $\mathrm{m}_{6}$ on Th. II-III.

\section{Hypogastrura tethyca Ellis, 1976}

Figs 11-14

Type material. Paratypes: Greece, Crete, leg. A.C. \& W.N. Ellis (deposited at the Naturalis Biodiversity Center, Netherland): 2 females (21008, 21010), 2 males (21011, 

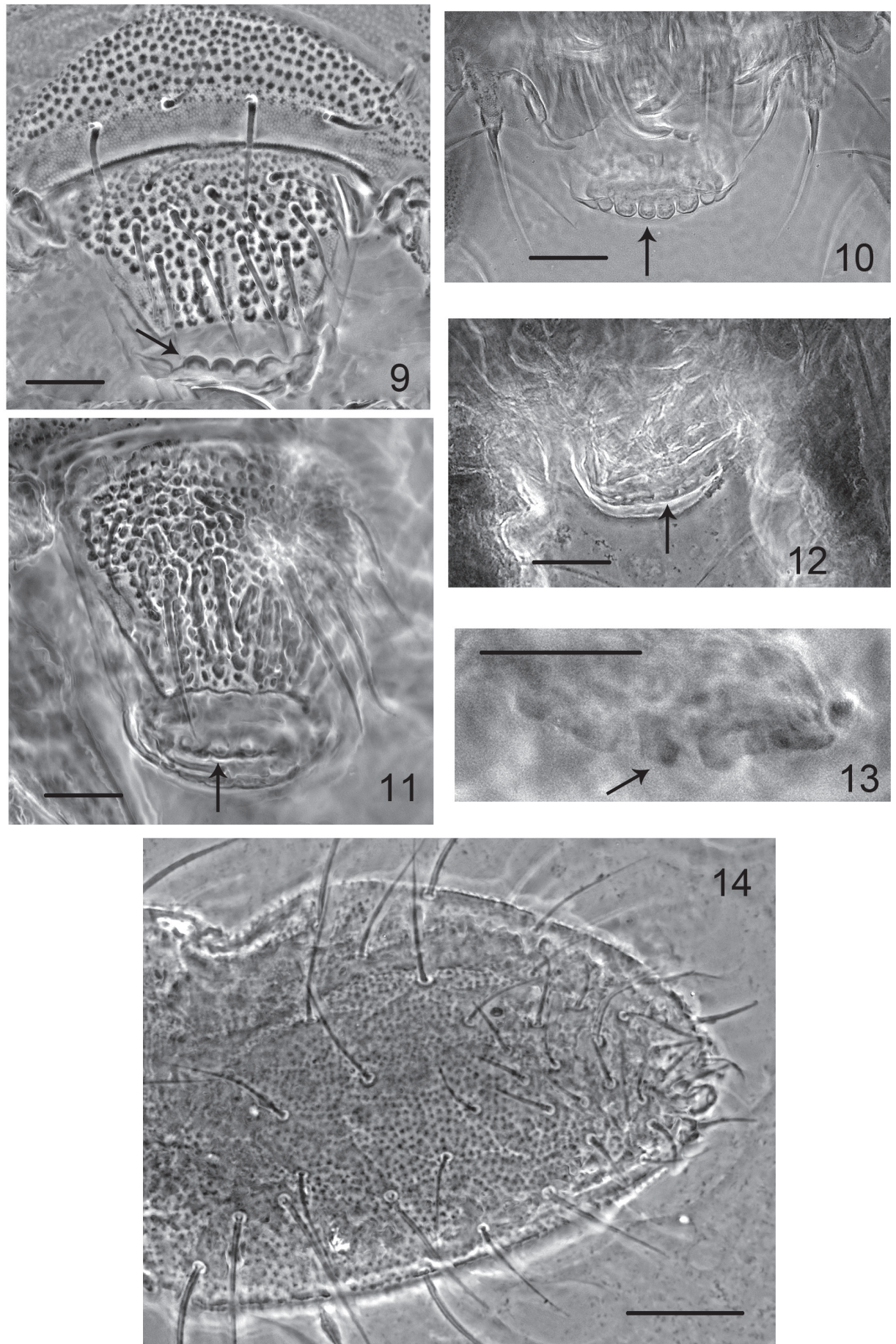

Figures 9-14. Hypogastrura ellisi sp. n. 9 labrum 10 apical part of labrum, H. tethyca: I I labrum, specimen from Azerbaijan $\mathbf{2} \mathbf{2}$ apical part of labrum, specimen from Crete $\mathbf{1 3}$ apical papillae, specimen from Crete $\mathbf{I}$ chaetotaxy of ventral side of Ant. IV. Black arrows indicate apical papillae. Scale bars: $0.01 \mathrm{~mm}$. 
21013), Knossos, loose loam, sparsely grown with grass and Oxalis pes-caprae L. at foot of a 4-m high cliff along road, 24.X.1972, 972.219; 3 females (21017, 21018, 21036), 3 males (21028, 21029, 21030), Knossos, collected manually under stones pieces of dead wood etc. 24.X.1972, 972.195; 1 female (21004), Iraklion, 25.X.1972, after heavy rains, loam, litter and rotting leaf bases under vigorous ruderal vegetation (Ecballium elaterium (L.) Rich., 972.233; 1 male (21015), Marathos, $15 \mathrm{~km} \mathrm{~W}$ of Iraklion, 26.X.1972, litter under Pistacia lentiscus in phrygana on weak north slope, 972.209; 3 females (20978, 20979, 20980), 7 males (20983, 20984, 20985, 20986, 20987, 20988, 20989), Malia, litter of Quercus coccifera in well-developed phrygana, 29.X.1972, 972.211.

Other material. Greece, Lesbos, leg. Ellis (deposited at the Naturalis Biodiversity Center, Netherland): 2 females (21069), 1 male (21070), Alifanta, 24.X.1973, 973219; 1 female (21075), Ayiásos, 16.XI.1973, 973334; 2 females (21072, 21073), 1 male (21074), Profitis Ilias, 13.X.1973, 973312; 1 female (21077), 1 male (21076), Agia Marina, 23.XI.1973, 973367; 1 female (21055), Mitilini, 19.X.1973, 973102. Azerbaijan, leg. Z.K.Rasulova (deposited at the Severtsov Institute of Ecology \& Evolution, Russian Academy of Sciences, Moscow): 7 females, 3 males (other data unknown).

Note. The description (Ellis 1976) and redescription (Babenko et al. 1994) of $H$. tethyca are highly informative; however, the examination of the types and other material allow us to add some more details. Hypogastrura tethyca has 10-18 granules between setae $\mathrm{p}_{1}$ on Abd. V, Ant. IV with three lateral and one dorsal long thin and curved blunt sensilla (sometimes 1-2 more in the dorsal group, longer and less curved, in arrangement as in H. ellisi sp. n., Fig. 4) and approximately ten short stiff sensilla truncate at the apex in the ventral file (Fig. 14), the postantennal organ 1.0-1.5 (usually 1.2) as long as the nearest ocellus, the labrum with delicate flat and hardly visible apical papilla (Figs 11-13), a maxillary outer lobe with two sublobal hairs, and large anal spines on high papillae (the ratio anal spine + basal papilla/inner edge of claws III 0.75-1.1).

Ellis (1976), looking for $H$. tethyca affinities, pointed out difficulties with its placement within the genus and compared it with a wide spectrum of species, including H. monticola Stach, 1946, H. aterrima, and also H. trybomi (Schött, 1893). Then, Babenko et al. (1994), based on specimens from Azerbaijan, put this species into the trybomi group. Although this concept seems well justified, $H$. tethyca, having a labrum with delicate apical papillae and tibiotarsi with long and clavate tenent hair, occupies a rather isolated position within the group. Undoubtedly, further research is needed to establish its relationships. The characteristics of the trybomi group and a key to the known species of the group are given below. H. tethyca is also similar to H. ellisi sp. n. They differ in the characters mentioned above.

\section{Notes on the trybomi group}

The trybomi group was created by Christiansen and Bellinger (1980) for five Nearctic species: H. irenae (Wray, 1953), H. lima Christiansen \& Bellinger, 1980, H. maynardi Christiansen \& Bellinger, 1980, H. oregonensis Yosii, 1960, and H. trybomi. Interest- 
ingly, subsequent studies (Fjellberg 1985, Babenko et al. 1994, Babenko and Fjellberg 2006) showed that $H$. trybomi sensu Christiansen and Bellinger (1980) rather referred to $H$. oregonensis. Afterwards, Babenko et al. (1994) supplemented the Christiansen and Bellinger (1980) definition with new essential features and enlarged the group by adding species recorded in Palearctic: H. maxillosa Babenko, 1994 and $H$. tethyca.

Presently, after the recent description of some new species (Skarżyński 2007, Jiang and Yin 2010, 2012, Jia et al. 2011) and the redescription of some poorly defined ones (Bernard 2015), twelve species can be included into the trybomi group sensu Christiansen and Bellinger $(1980,1998)$ and Babenko et al. (1994): H. analpapillata Jiang \& Yin, 2012, H. hargrovei Skarżyński, 2007, H. gravesi Wray, 1971, H. heptasetata Jiang \& Yin, 2010, H. hexasetata Jiang \& Yin 2010, H. irenae, H. lima, $H$. manghe Jia, Skarżyński \& Konikiewicz, 2011, H. maxillosa, H. oregonensis, $H$. tethyca, and $H$. trybomi. Another one, $H$. maynardi, can also be considered a potential member of this group. However, a modern redescription of this species is necessary to solve this problem (Christiansen and Bellinger 1998).

These species have fine cuticular granulation of the body (7-18 cuticular granules between setae $\mathrm{p}_{1}$ on Abd. V), long and thin blunt Ant. IV sensilla arranged in two groups: 2-3 lateral and 1-8 dorsal (often difficult to distinguish from ordinary setae), a labrum without distinct apical papillae, a postantennal organ from slightly smaller to slightly larger than the neighboring ocellus, one usually short pointed tenent hair on the tibiotarsi (only in $H$. tethyca clavate), a broad basal empodial lamella, a quadridentate retinaculum, dens with 6-7 setae and without tooth-like granules and ventro-apical swelling, a mucro without distinct subapical tooth, setae $\mathrm{m}_{6}$ on Th. II-III present, $\mathrm{m}-$ setae on Abd. $\mathrm{V}$ absent, and usually $4+4$ setae on the ventral tube (only in $H$. trybomi 7-9 + 7-9). Moreover, some of them have the head of the maxilla with prolonged lamellae, a maxillary outer lobe with only one sublobal hair, and Ant. IV with a developed ventral file of sensilla. Members of this group differ in the characters summarized in Table 1 and a key.

Considering their morphology, one can conclude that three species: $H$. tethyca, $H$. trybomi, and $H$. hargrovei, occupy rather isolated positions. Especially the first one due to the reasons mentioned above, the second one because of the ventral tube with numerous setae and tibiotarsi with relatively long, but pointed, tenent hair (judging from fig. 111 in Fjellberg (1985) and fig. 17.5 in Babenko et al. (1994)), and the third one due to highly modified mouthparts: the labrum elongated, the head of the maxilla with only two teeth and prolonged lamellae, the labial palp without papilla $\mathrm{C}$, with hypostomal setae set on a narrow long projection, and a weakly developed ventral file of Ant. IV sensilla.

The remaining nine species form two subgroups: Eastern Palearctic (H. analpapillata, $H$. heptasetata, $H$. hexasetata, $H$. manghe, and $H$. maxillosa), with distinctly prolonged maxillary lamellae (lamellae 1, 2, 4, 5 exceed maxillary teeth) and fine cuticular granulation on dens, and Nearctic (H. gravesi, H. irenae, H. lima, and H. oregonensis), characterized by maxillary lamellae longer than in $H$. tethyca or $H$. trybomi (maxilla of the tullbergi type) but distinctly shorter than in representatives of the previous subgroup (at most lamellae 1 and 2 exceed maxillary teeth) and dens (at least in distal part) with coarse cuticular granulation. 
Table I. Morphological differences between the members of the trybomi group. Data after: $H$. analpapillata - Jiang and Yin (2012); H. hargrovei - Skarżyński (2007); H. gravesi - Bernard (2015); H. heptasetata - Jiang and Yin (2010); H. hexasetata - Jiang and Yin (2010); H. irenae - Bernard (2015); H. lima - Christiansen and Bellinger (1998), Skarżyński (2007); H. manghe - Jia et al. (2011); H. maxillosaBabenko et al. (1994); H. oregonensis - Yosii (1960), Fjellberg (1985), Babenko et al. (1994), Christiansen and Bellinger (1998), Skarżyński (2007); H. tethyca - Ellis (1976), Babenko et al. (1994) and own data; H. trybomi - Fjellberg (1985), Babenko et al. (1994). Abbreviations: blAnt -number of blunt sensilla on Ant. IV, venAnt - number/shape of sensilla in ventral file on Ant. IV (tips: $\mathrm{p}$ - pointed, $\mathrm{t}$ - truncate, b broadened and flattened), lam - prolonged maxillary lamellae 4 and 5, sl - number of sublobal hairs in maxillary outer lobe, labC - papilla C in labial palp, vhead - number of axial setae on ventral side of head, $\mathrm{m} 2$ - setae $\mathrm{m}_{2}$ on Th. II., setD - number of setae on dens, granD - coarse cuticular granulation on dens (at least in distal part), As/pap - ratio anal spine/basal papilla.

\begin{tabular}{|c|c|c|c|c|c|c|c|c|c|c|}
\hline Species & blAnt & venAnt & lam & sl & labC & vhead & $\mathrm{m} 2$ & setD & granD & As/pap \\
\hline H. analpapillata ${ }^{1}$ & 7 & $35-50 / \mathrm{p}$ & + & 2 & + & $3+3$ & + & 7 & $+?$ & 0.4 \\
\hline H. graves $i^{2}$ & $4-5$ & $40-50 / b$ & - & 2 & + & $?$ & + & 7 & + & $1.5-2$ \\
\hline H. hargrovei ${ }^{3}$ & 6 & ca. $10 / \mathrm{p}$ & + & 1 & - & $2+2$ & - & 6 & - & ca. 1 \\
\hline H. heptasetata ${ }^{4}$ & 10 & $10-15 / \mathrm{p}$ & + & 1 & - & $2+2$ & + & 7 & - & 1.8 \\
\hline H. hexasetata & $8-10$ & $30-55 / \mathrm{p}$ & + & 1 & + & $3+3$ & + & 6 & - & ca. 1 \\
\hline H. irenae & 8 & $53-58 / b^{5}$ & - & 1 & + & $?$ & + & 7 & + & ca. 1 \\
\hline H. lima & $7-8$ & ca. $20 / \mathrm{b}$ & - & $?$ & $?$ & $?$ & $?$ & 7 & + & $1.5-2$ \\
\hline H. manghe ${ }^{6}$ & $9-11$ & $30-45 / \mathrm{b}$ & + & 1 & + & $3+3$ & + & 6 & - & ca. 1 \\
\hline H. maxillosa & 7-9 & ca. $20 / ?^{7}$ & + & 2 & $?$ & $3+3$ & - & 7 & - & ca. 1 \\
\hline H. oregonensis & $7-9$ & $20-35 / b^{8}$ & - & 2 & + & $3+3$ & $+/-$ & $6-7$ & + & ca. 1 \\
\hline H. tethyca ${ }^{9}$ & $4-6$ & ca. $10 / \mathrm{t}$ & - & 2 & + & $3+3$ & + & 7 & - & ca. 1 \\
\hline H. trybomi ${ }^{10}$ & ? & ca. $10 / \mathrm{p}$ & - & 2 & ? & $3+3$ & - & 7 & - & ca. 1 \\
\hline
\end{tabular}

${ }^{1}$ Basal papillae of anal spines strongly granulated and fused to each other

${ }^{2}$ Anal spines blunt, rounded or truncated apically

${ }^{3}$ Labrum elongated, head of maxilla with two teeth, hypostomal setae of labial palp set on a narrow long projection

${ }^{4}$ Maxillary lamellae 6 longer than teeth

${ }^{5}$ Sensilla thick

${ }^{6}$ Ant. IV with trilobed apical vesicle

${ }^{7}$ After Babenko et al. (1994: fig. 20.6)

${ }^{8}$ After Fjellberg (1985: fig. 86) and Babenko et al. (1994: fig. 19.2)

${ }^{9}$ Labrum with flat delicate hardly visible apical papillae, tibiotarsi with clavate tenent hair

${ }^{10}$ Ventral tube with 7-9 + 7-9 setae, tibiotarsi with relatively long, but pointed tenent hair

The general distribution of the group is Holarctic; however, only one member, H. oregonensis, lives in both Palearctic and Nearctic (W Nearctic - USA: Alaska, California, Idaho, Montana, Oregon, Washington; Canada: Northwest Territories; E Palearctic - Russia: Chukotka; Japan) (Hammer 1953, Yosii 1960, Fjellberg 1985, Babenko et al. 1994, Christiansen and Bellinger 1998, Babenko and Fjellberg 2006). The remaining species have more restricted geographic ranges. $H$. tethyca occurs in Greece (Crete, Lesbos) and Azerbaijan; H. trybomi lives in high Arctic regions of Palearctic (from Franz Josef Land to Wrangel Island, Babenko and Fjellberg 2006); 
H. maxillosa is known from one location in Middle Siberia (Tomskaya oblast) (Babenko et al. 1994). Four species occur in China: H. analpapillata (Yunnan Province) (Jiang and Yin 2012), H. heptasetata (Jiangsu Province) (Jiang and Yin 2010), H. hexasetata (Hubei Province) (Jiang and Yin 2010), and H. manghe (Shanxi Province) (Jia et al. 2011), and four in the eastern states of the USA: H. gravesi (North Carolina) (Bernard 2015), H. hargrovei (South Carolina) (Skarżyński 2007), H. irenae (North Carolina) (Bernard 2015), and H. lima (Pennsylvania, Maryland, New York) (Christiansen and Bellinger 1998).

\section{Key to Hypogastrura species of the trybomi group}

$1 \quad$ Tenent hair on tibiotarsi pointed

- $\quad$ Tenent hair on tibiotarsi clavate H. tethyca Ellis, 1976

Ventral tube with $4+4$ setae 3

Ventral tube with 7-9 + 7-9 setae. H. trybomi (Schött, 1893)

Labrum short. Ant. IV with 4-5 blunt sensilla, anal spines blunt, rounded or truncated apically H. gravesi Wray, 1971

Anal spines shorter than or subequal to papillae....

Anal spines 1.5-2 times as long as papillae.... H. lima Ch \& B, 1980

Maxillary outer lobe with one sublobal hair H. irenae (Wray, 1953) Maxillary outer lobe with two sublobal hairs H. oregonensis Yosii, 1960 Th. II with setae $m_{2}$ present

Th. II with setae $m_{2}$ absent

H. maxillosa Babenko, 1994 (in Babenko et al. 1994)

10 Ant. IV with 10-15 sensilla in ventral file, head ventrally with $2+2$ axial setae, labial palp with papilla $\mathrm{C}$ absent, maxillary outer lobe with one sublobal hair, ratio anal spine : basal papilla $1.8 \ldots . . H$. heptasetata Jiang \& Yin 2010 Ant. IV with 35-50 sensilla in ventral file, head ventrally with $3+3$ axial setae, labial palp with papilla $\mathrm{C}$ present, maxillary outer lobe with two sublobal hairs, ratio anal spine : basal papilla 0.4

H. analpapillata Jiang \& Yin, 2012

11 Ant. IV with simple apical vesicle and sensilla in ventral file pointed

$H$. hexasetata Jiang \& Yin 2010

Ant. IV with trilobed apical vesicle and sensilla in ventral file broadened and flattened at tips 


\section{Acknowledgements}

We would like to express our sincere thanks to Willem Hogenes (Naturalis Biodiversity Center, Netherland) for the loan of the $H$. tethyca and $H$. ellisi sp. n. specimens. We also thank Anatoly Babenko (The Severtsov Institute of Ecology \& Evolution, Russian Academy of Sciences, Moscow) for information on H. tethyca from Azerbaijan and loan of material. We are grateful to the reviewers Anatoly Babenko and Arne Fjellberg for their insightful comments on the manuscript.

\section{References}

Babenko AB, Chernova NM, Potapov MB, Stebaeva SK (1994) Collembola of Russia and adjacent countries: Family Hypogastruridae. Nauka, Moscow, 336 pp.

Babenko A, Fjellberg A (2006) Collembola septentrionale. A catalogue of springtails of the Arctic regions. KMK Scientific Press Ltd., Moscow, 190 pp.

Bellinger P, Christiansen KA, Janssens F (1996-2017) Checklist of the Collembola of the World. Available from: http://www.collembola.org (date of access: 30.VI.2017).

Bernard EC (2015) Redescriptions of Hypogastruridae and Onychiuridae (Collembola) described by David L. Wray. Zootaxa 3918: 301-338. https://doi.org/10.11646/ zootaxa.3918.3.1

Bourlet A (1839) Mémoires sur les Podures. Mémoires de la Société des sciences de l'agriculture et des arts de Lille 1: 377-417.

Christiansen K, Bellinger P (1980) The Collembola of North America north of the Rio Grande. Grinnell College, Grinnell, 1321 pp.

Christiansen K, Bellinger P (1998) The Collembola of North America north of the Rio Grande. A taxonomic analysis. Grinnell College, Grinnell, 1520 pp.

Ellis WN (1976) Autumn fauna of Collembola from Central Crete. Tijdschrift voor Entomologie 119: 221-326.

Fjellberg A (1984) Maxillary structures in Hypogastruridae (Collembola). Annales de la Société Royale Zoologique de Belgique 114: 89-99.

Fjellberg A (1985) Arctic Collembola. 1. The collembolan fauna of Alaska: Families Poduridae, Hypogastruridae, Odontellidae, Brachystomellidae and Neanuridae. Entomologica Scandinavica Suppl. 21: 1-126.

Fjellberg A (1999) The Labial Palp in Collembola. Zoologischer Anzeiger 237: 309-330.

Hammer M (1953) Investigations on the microfauna of Northern Canada, part II. Collembola. Acta Antarctica 6: 5-107.

Jia J, Skarżyński D, Konikiewicz M (2011) A taxonomic study on Hypogastrura Bourlet, 1839 (Collembola, Hypogastruridae) from China. Zootaxa 2981: 56-62.

Jiang J, Yin W (2010) Two new Hypogastrura species (Hypogastruridae, Collembola) from China. Zootaxa 2542: 48-60.

Jiang J, Yin W (2012) New Hypogastrura species and new distributional data for Hypogastrura distincta (Axelson 1902) from China (Collembola: Poduromorpha: Hypogastruridae). An- 
nales de la Société entomologique de France 48: 115-122. https://doi.org/10.1080/0037 9271.2012.10697759

Skarżyński D (2007) Hypogastrura hargrovei sp. n., a new species of the family Hypogastruridae (Collembola) with highly modified mouthparts. Insect Systematic and Evolution 38: 201-204.

Skarżyński D (2009) Reassessment of the taxonomic position of Hypogastrura monticola Stach, 1946 (Collembola, Hypogastruridae). Soil Organisms 81: 77-83.

Schött H (1893) Zur Systematic und Verbreitung palearctischen Collembolen. Kungliga Svenska Vetenskapsakademiens Handlingar 25: 1-100.

Stach J (1946) Ten new species of Collembola from the Alps and alpine foreland. Academia Polona Litterarum et Scientiarum Acta Musei Historiae Naturalis 5: 1-40.

Swan DC (1936) Berlese's Fluid: Remarks upon its Preparation and use as a Mounting Medium. Bulletin of Entomological Research 27: 389-391. https://doi. org/10.1163/187631207794760985

Thibaud J-M, Schulz H-J, Gama Assalino MM da (2004) Hypogastruridae. In: Dunger W (Ed.) Synopses on Palaearctic Collembola. Vol. 4, Abhandlungen und Berichte des Naturkundemuseums Görlitz 75: 1-287.

Wang F, Christiansen K, Chen J-X (2003) A New Species of Pseudosinella from Xinjiang, China (Collembola: Entomobryidae). Journal of the Kansas Entomological Society 76: 603-609. Wray DL (1953) New North Carolina Collembola. Bulletin of the Brooklyn Entomological Society 48: 82-83.

Wray DL (1971) A unique species of the genus Hypogastrura from North Carolina (Collembola, Poduridae). Entomological News 82: 147-150.

Yosii R (1960) Studies on the Collembolan genus Hypogastrura. American Midland Naturalist 64: 257-281. https://doi.org/10.2307/2422661 